Erratum

\title{
Erratum: Abidar, S.; et al. The Aqueous Extract from Ceratonia siliqua Leaves Protects against 6-Hydroxydopamine in Zebrafish: Understanding the Underlying Mechanism. Antioxidants 2020, 9, 304
}

\author{
Sara Abidar ${ }^{1}$, Razvan Stefan Boiangiu ${ }^{2} \mathbb{D}$, Gabriela Dumitru ${ }^{2, *,+}$, Elena Todirascu-Ciornea ${ }^{2,+}$, \\ Amina Amakran ${ }^{1}$, Oana Cioanca ${ }^{3,+}\left(\mathbb{D}\right.$, Lucian Hritcu ${ }^{2, *} \mathbb{C}$ and Mohamed Nhiri ${ }^{1}$ \\ 1 Laboratoire de Biochimie et Génétique Moléculaire, Faculté des Sciences et Techniques, \\ Université Abdelmalek Essaadi, Tanger Principal BP 416, Morocco; sara.abidar91@gmail.com (S.A.); \\ amakran_amina@hotmail.com (A.A.); med.nhiri@gmail.com (M.N.) \\ 2 Department of Biology, Faculty of Biology, Alexandru Ioan Cuza University of Iasi, 700506 Iasi, Romania; \\ boiangiu.razvan@yahoo.com (R.S.B.); ciornea@uaic.ro (E.T.-C.) \\ 3 Department of Pharmacognosy, Faculty of Pharmacy, "Grigore T. Popa” University of Medicine and Pharmacy, \\ 16 University Street, 700115 Iasi, Romania; oana.cioanca@gmail.com \\ * Correspondence: gabriela.dumitru@uaic.ro (G.D.); hritcu@uaic.ro (H.L.); \\ Tel.: +40-232-201-522 (G.D.); +40-232-201-666 (H.L.) \\ + These authors contributed equally to this work.
}

Published: 9 June 2020

The authors wish to make the following correction to their paper [1]:

The number corresponding to the affiliation of Lucian Hritcu had been changed from:

Lucian Hritcu ${ }^{1, *}$

to

Lucian Hritcu ${ }^{2, *}$

The authors would like to apologize for any inconvenience caused to the readers by these changes. The changes do not affect the scientific results.

\section{Reference}

1. Abidar, S.; Boiangiu, R.S.; Dumitru, G.; Todirascu-Ciornea, E.; Amakran, A.; Cioanca, O.; Hritcu, L.; Nhiri, M. The Aqueous Extract from Ceratonia siliqua Leaves Protects against 6-Hydroxydopamine in Zebrafish: Understanding the Underlying Mechanism. Antioxidants 2020, 9, 304. [CrossRef] [PubMed]

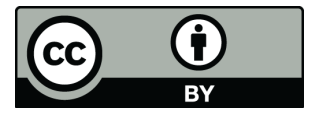

(C) 2020 by the authors. Licensee MDPI, Basel, Switzerland. This article is an open access article distributed under the terms and conditions of the Creative Commons Attribution (CC BY) license (http://creativecommons.org/licenses/by/4.0/). 